\title{
A RANDOMISED STUDY OF LOW-DOSE ORAL MISOPROSTOL AND INTRACERVICAL PROSTAGLANDIN E2 GEL FOR CERVICAL RIPENING AND LABOUR INDUCTION IN TERM PREGNANCY
}

\author{
Sandhya Jain ${ }^{1}$, Shikha Pasrija2, Shilpa Sakure ${ }^{3}$, Nivedita Sarda ${ }^{4}$
}

${ }_{1}^{1}$ CMO (NFSG), Department of Obstetrics and Gynaecology, Dr. Baba Saheb Ambedkar Hospital and Medical College, Delhi, India.

${ }^{2}$ Specialist, Department of Obstetrics and Gynaecology, Dr. Baba Saheb Ambedkar Hospital and Medical College, Delhi, India.

${ }_{3}^{3}$ Senior Resident, Department of Obstetrics and Gynaecology, Dr. Baba Saheb Ambedkar Hospital and Medical College, Delhi, India.

4Professor, Department of Obstetrics and Gynaecology, Dr. Baba Saheb Ambedkar Hospital and Medical College, Delhi, India.

\section{BACKGROUND}

ABSTRACT

Labour induction is one of the most frequent interventions all over the world in pregnant women. The rate of induction varies by location and in many centres, it is currently more than $20 \%$. When the benefits of expeditious delivery are greater than the risks of continuing the pregnancy, inducing labour can be justified as a therapeutic intervention. The current study was done with the objective of comparing the efficacy, acceptability and safety of low-dose oral misoprostol tablet (25 ugm PGE1) and intracervical dinoprostone (PGE2) for labour induction and cervical ripening in women at term. In developing countries with low resources, misoprostol could be the preferred drug because of low cost and easy storage; however, monitoring the induced labour is a challenge.

Aims and Objectives- To compare efficacy, acceptability and side effects of low-dose oral misoprostol with that of intracervical dinoprostone for cervical ripening and induction of labour.

\section{MATERIALS AND METHODS}

A prospective, randomised, controlled study wherein 100 pregnant women admitted to labour ward at 37 weeks or beyond with a single live foetus for induction of labour were included. The enrolled women were randomly divided into two equal Groups $A$ and B. Group A women received oral tab Misoprostol 25 ugm every 2 hours for a maximum of 6 doses. Group B women received 0.5 mg intracervical dinoprostone gel 6 hourly, for a maximum of 3 doses. Outcomes in terms of improvement in Bishop's score, induction to delivery interval, number of doses required, requirement of any other means of ripening, induction and/or augmentation and mode of delivery were noted. Side effects and complications were compared. Foetal outcomes in terms of Apgar score and need for NICU admission was compared. The results observed were subjected to statistical analysis by SPSS: Chi-square/ Fisher's Exact test and Unpaired t-test.

\section{RESULTS}

The two groups were comparable in terms of age, parity, gravidity, period of gestation at induction and reasons for induction of labour. Successful priming was achieved in $100 \%$ women in Group A and $86 \%$ women in Group B. The 'p' value was 0.003 , which is statistically significant. The number of women with a favourable score $(\geq 6)$ was significantly higher in Group A. Successful induction was achieved in $88 \%$ and $66 \%$ women in Groups A and B respectively. The mean induction to delivery interval was shorter in Group A. Vaginal delivery was the outcome in $92 \%$ women with misoprostol induction and $74 \%$ women with dinoprostone induction. Side effects of prostaglandin inductions when compared in two groups showed no statistically significant differences.

\section{CONCLUSION}

Low-dose oral misoprostol is more effective than dinoprostone gel for cervical priming and labour induction without compromising safety. It has an advantage of decreasing the need of additional measures to achieve vaginal delivery, lower cost and patient acceptability as shown by VAS score.

\section{KEYWORDS}

Cervical Ripening; Labour Induction; Misoprostol; Dinoprostone.

HOW TO CITE THIS ARTICLE: Jain S, Pasrija S, Sakure S, et al. A randomised study of low-dose oral misoprostol and intracervical prostaglandin E2 gel for cervical ripening and labour induction in term pregnancy. J. Evolution Med. Dent. Sci. 2018;7(16):20232028, DOI: $10.14260 /$ jemds/2018/455

\section{BACKGROUND}

Labour induction is one of the most frequent interventions all over the world in pregnant women. The rate of induction

'Financial or Other Competing Interest': None.

Submission 24-02-2018, Peer Review 30-03-2018,

Acceptance 04-04-2018, Published 16-04-2018.

Corresponding Author:

Dr. Shikha Pasrija,

CA-16, Tagore Garden,

New Delhi-110027, India.

E-mail: shikhapasrija@gmail.com

DOI: $10.14260 /$ jemds $/ 2018 / 455$ varies by location and in many centres it is currently more than $20 \% .{ }^{1}$ The pros and cons of labour induction must be weighed against the potential maternal and foetal risks associated with this procedure. When the benefits of expeditious delivery are greater than the risks of continuing the pregnancy, inducing labour can be justified as a therapeutic intervention. ${ }^{2}$ The aim of successful induction is to achieve vaginal delivery with good neonatal outcome in an acceptable timeframe and with minimum maternal discomfort or side effects. A ripened cervix and effective uterine contractions are two essential determinants for success in labour outcomes. ${ }^{3}$ Nulliparous women with a low 
Bishop's score are particularly at a high risk of caesarean delivery when labour is induced, hence the need of a good cervical ripening agent. 4,5

Medications that ripen the cervix in a short period of time play a significant role in modern obstetrics. There have been many studies to evaluate the efficacy of misoprostol for labour induction in various doses, routes and intervals of administration, suggesting that misoprostol is effective, but there is still a concern that misoprostol may increase the rates of tachysystole and hyperstimulation and a search for ideal dose and mode is still on. ${ }^{6}$ Although, low-dose misoprostol is recommended by $\mathrm{WHO}^{1} \mathrm{FIGO}^{7}$ and $\mathrm{SOGC}^{8}$ it is still not approved by FDA for this indication. The availability of low-dose misoprostol tablet is restricted to a few countries.

The current study was done with the objective of comparing the efficacy, acceptability and safety of low-dose oral misoprostol tablet (25 ugm PGE1) and intracervical dinoprostone (PGE2) for labour induction and cervical ripening in women at term. In developing countries with low resources, misoprostol could be the preferred drug because of low cost and easy storage; however, monitoring the induced labour is a challenge.

\section{MATERIALS AND METHODS}

A prospective, randomised, controlled study was conducted at a district hospital of New Delhi over a period of one year. Sample size was calculated based on assumptions that the two groups are of same size and the standard deviations are the same. Keeping the power of test as $90 \%$ and level of significance as $99 \%$, a sample size of 50 in each group was obtained. 100 women admitted to labour ward with a single foetus in cephalic presentation and period of gestation 37 or more weeks with an indication for induction of labour were included in the study after an informed written consent. Exclusion criteria were contraindications for vaginal delivery, previous uterine surgery, malpresentation, grand multiparity, antepartum haemorrhage, abnormal foetal heart rate pattern, known allergy to prostaglandins, multiple pregnancies, medical illness in mother contraindicating the use of prostaglandins and women with $\mathrm{Hb}<8 \mathrm{gm} \%$. Detailed history including obstetric history, menstrual history, surgical and medical history was recorded. General physical and systemic examination was done. Abdominal examination assessed the fundal height, lie, presentation, amount of liquor and foetal heart sounds and vaginal examination confirmed presentation and assessed Bishop's score. Gestational age was confirmed by last menstrual period and/or Ultrasound.

The enrolled women were randomly assigned into two study groups using computer generated random numbers. In Group A ( $=50)$, women received Tab. Misoprostol 25 ugm orally repeated every 2 hours for a maximum of 6 doses. In Group B $(\mathrm{N}=50)$, women received $0.5 \mathrm{mg}$ intracervical dinoprostone gel repeated every 6 hours for a maximum of 3 doses. Partogram was maintained in all patients, foetal monitoring was done with CTG and modified Bishop's score was assessed at $0,4,6,8,10$ and 12 hrs. Need for any additional method of induction or augmentation was noted.

Maternal outcomes in terms of improvement in the modified Bishop's score with time intervals, induction to delivery interval, number of doses required, requirement of any other means of induction and/ or augmentation and mode of delivery was noted. Foetal outcomes in terms of Apgar score and need for NICU admission was recorded. Side effects and complications of two induction modes were recorded. Maternal experience and satisfaction was recorded using a VAS Likert scale of 1 - 5.

\section{Following Definitions and Criteria were used to calculate the Results}

- Successful Induction: If vaginal delivery was achieved within 24 hrs. of induction.

- Successful Priming: If cervix becomes favourable at 12 hrs. of induction.

- Failed Induction: When women does not go in labour even after 6 doses of misoprostol or 3 doses of dinoprostone.

- Partial Failure of Induction: Partial failure will be considered if women require any other means of augmentation for delivery.

- Uterine hyperstimulation include Tachysystole or Hypersystole with or without foetal heart rate changes.

- Tachysystole: Defined as 5 or more uterine contractions in 10 mins for at least 20 mins period.

- Hypersystole: Defined as single contraction lasting 2 mins or more in duration.

The results observed were subjected to statistical analysis by SPSS software: Chi-square/ Fisher's exact test and Unpaired ' $\mathrm{t}$ ' test.

\section{RESULTS}

The age of the patients ranged from 19 - 36 years, mean being $25.58 \pm 2.87$ in Group A and 25.04 \pm 3.45 in Group B. Gravidity of women ranged from $1-6 ; 64 \%$ and $60 \%$ women in Group A and B respectively were primigravidae. Gestational age of women ranged from $37+2$ wks to $41+6$ wks. Mean gestational age was $39.62 \pm 1.27$ and $39.14 \pm 1.37$ in Group A and B respectively. The two groups were comparable in terms of age, parity, gravidity, period of gestation at induction and reasons for induction of labour (Table 1).

The most common indication for induction was postdates $(48 \%)$ followed by premature rupture of membranes (41\%).

The mean modified Bishop's score at 0 hour was similar in two groups $3.16 \pm 1.28$ in Group A and $2.96 \pm 1.52$ in Group B; however, subsequent scores were higher for Group A and the difference was statistically significant (Table 2).

The number of women with a favourable score, that is $\geq 6$ was significantly higher in Group A at 6, 8, 10 and 12 hours (Table 3). Successful priming that is a favourable score at 12 hrs. was achieved in 100\% women in Group A and $86 \%$ women in Group B. The ' $p$ ' value was 0.003 , which was statistically significant.

Oxytocin for augmentation was required in $28 \%$ and $40 \%$ women in Group A and B respectively. 'P' value was 0.032 , which was statistically significant.

In Group A 28\% women responded to 6 tablets, 24\% responded to 2 tablets, $22 \%$ needed 3 tablets, $12 \%$ needed 4 
tablets, $12 \%$ needed 5 tablets and $2 \%$ needed only one tablet. In Group B 42\% each needed 1 and 3 gel insertions, while another $16 \%$ needed 2 gel insertions.

The mean induction to delivery interval in Group A and B was $10.4 \pm 6.31 \mathrm{hrs}$. and $13.17 \pm 7.34$ hours respectively. The difference was statistically significant, 'p' value being 0.034 (Table 4). At 12 hours 67.4\% women had delivered in Group A in contrast with $46 \%$ in Group B and when compared at 18 hours $91.3 \%$ women had delivered as against $75 \%$ in Group B. This is a big difference.

Successful induction was achieved in $88 \%$ and $66 \%$ women in Groups A and B respectively. Failed induction resulted in $12 \%$ and $34 \%$ women. Both differences were found to be statistically significant, 'p' value being 0.004 in each. Vaginal delivery was the outcome in $92 \%$ women with misoprostol induction and 74\% women with dinoprostone induction which is significant ( $\mathrm{p}$ value $=0.008$ ).

Side effects of prostaglandin inductions when compared in two groups showed no statistically significant differences, vomiting being the most common followed by postpartum haemorrhage and tachysystole (Table 5).

There was a significant difference in the Apgar scores of babies in Group A and B with babies in Group A faring better (Table 6).

The mean VAS score in women of Group A was $4.20 \pm$ 0.93 and in Group B was $3.3 \pm 1.39$, 'p' value was 0.000 making it significant. Thus, maternal satisfaction was higher in Group A.

\begin{tabular}{|c|c|c|c|}
\hline Characteristic & $\begin{array}{c}\text { Group A } \\
\text { Mean } \pm \text { SD }\end{array}$ & $\begin{array}{c}\text { Group B } \\
\text { Mean } \pm \text { SD }\end{array}$ & P value \\
\hline Age in Years & $25.58 \pm 2.87$ & $25.04 \pm 3.45$ & 0.20 \\
\hline Parity & $01.16 \pm 1.36$ & $00.90 \pm 0.97$ & \\
Primigravida (\%) & 64 & 60 & 0.34 \\
Multigravida (\%) & 36 & 40 & \\
\hline Mean Gestational Age at & $39.62 \pm 1.26$ & $39.14 \pm 1.38$ & 0.04 \\
Induction in Weeks & & & \\
\hline Indication of Induction & 44 & 28 & 0.05 \\
Postdates (\%) & 30 & 28 & 0.41 \\
PROM (\%) & 10 & 2 & \\
IUGR (\%) & \multicolumn{3}{|c|}{ Table 1. Clinical Profile } \\
\hline \multicolumn{4}{|l}{}
\end{tabular}

\begin{tabular}{|c|c|c|c|}
\hline \multirow{2}{*}{$\begin{array}{c}\text { Number of } \\
\text { Hrs. since } \\
\text { Induction }\end{array}$} & Modified Bishop Score & \\
\cline { 2 - 3 } & Group A & Group B & \multirow{2}{*}{ P-value } \\
\cline { 2 - 3 } 0 hrs. & $3.16 \pm 1.28$ & $2.96 \pm 1.52$ & 0.240 \\
$4 \mathrm{hrs}$. & $5.40 \pm 2.96$ & $4.09 \pm 2.68$ & 0.014 \\
$6 \mathrm{hrs}$. & $6.47 \pm 2.83$ & $5.07 \pm 2.74$ & 0.014 \\
$8 \mathrm{hrs}$. & $7.45 \pm 2.34$ & $6.41 \pm 2.74$ & 0.049 \\
$10 \mathrm{hrs}$. & $8.26 \pm 2.05$ & $6.88 \pm 2.23$ & 0.011 \\
$12 \mathrm{hrs}$. & $9.17 \pm 1.69$ & $8.00 \pm 2.68$ & 0.049 \\
\hline Table 2. Improvement in Modified Bishop's Scores with \\
\multicolumn{3}{|c|}{ Time } \\
\hline
\end{tabular}

\begin{tabular}{|c|c|c|c|c|c|}
\hline \multirow{2}{*}{$\begin{array}{c}\text { Number of } \\
\text { Hrs. since }\end{array}$ Induction } & \multicolumn{3}{|c|}{ Modified Bishop's Score $\geq \mathbf{6}$} & \multirow{2}{*}{ Group A } & \multicolumn{2}{|c|}{ Group B } & \multirow{2}{*}{ P-value } \\
\cline { 2 - 5 } & $\mathbf{N}$ & $\mathbf{\%}$ & $\mathbf{N}$ & $\mathbf{\%}$ & \\
\hline 0 hrs. & 0 & 0.00 & 0 & 0.00 & - \\
4 hrs. & 22 & 37.78 & 14 & 23.40 & 0.067 \\
6 hrs. & 32 & 52.63 & 23 & 35.71 & 0.041 \\
8 hrs. & 46 & 86.21 & 32 & 53.85 & 0.001 \\
10 hrs. & 49 & 95.65 & 36 & 58.82 & 0.001 \\
12 hrs. & 50 & 100.00 & 43 & 86.00 & 0.003 \\
\hline
\end{tabular}

Table 3. Women with Favourable Bishop's Score

\begin{tabular}{|c|c|c|c|c|c|c|}
\hline \multirow{2}{*}{$\begin{array}{c}\text { Induction } \\
\text { Delivery } \\
\text { Interval (hrs.) }\end{array}$} & \multicolumn{3}{|c|}{ Group A } & \multicolumn{2}{|c|}{ Group B } & \multirow[b]{2}{*}{ P-value } \\
\hline & $\mathbf{N}$ & \multicolumn{2}{|c|}{$\%$} & $\mathbf{N}$ & $\%$ & \\
\hline $0-6$ & 13 & \multicolumn{2}{|c|}{28.26} & 8 & 21.62 & 0.245 \\
\hline $6-12$ & 18 & \multicolumn{2}{|c|}{39.13} & 9 & 24.32 & 0.076 \\
\hline $12-18$ & 11 & \multicolumn{2}{|c|}{23.91} & 11 & 29.73 & 0.275 \\
\hline $18-24$ & 2 & \multicolumn{2}{|c|}{4.35} & 5 & 13.51 & 0.068 \\
\hline$>24$ & 2 & \multicolumn{2}{|c|}{4.35} & 4 & 10.81 & 0.129 \\
\hline Total & 46 & \multicolumn{2}{|c|}{100} & 37 & 100 & \\
\hline Mean \pm SD & \multicolumn{3}{|c|}{$10.40 \pm 6.31$} & \multicolumn{2}{|c|}{$13.71 \pm 7.34$} & 0.034 \\
\hline \multicolumn{7}{|c|}{ Table 4. Comparison of Induction Delivery Interval } \\
\hline \multirow{2}{*}{\multicolumn{2}{|c|}{ Side Effect }} & \multicolumn{2}{|c|}{ Group A } & \multicolumn{2}{|c|}{ Group B } & \multirow{2}{*}{ P-value } \\
\hline & & $\mathbf{N}$ & $\%$ & $\mathbf{N}$ & $\%$ & \\
\hline \multirow{3}{*}{$\begin{array}{c}\text { Diarrhoea } \\
\text { Fever } \\
\text { Vomiting }\end{array}$} & & 2 & 4 & 3 & 6 & 0.323 \\
\hline & & 0 & 0 & 2 & 4 & 0.077 \\
\hline & & 6 & 12 & 7 & 14 & 0.383 \\
\hline Hyperstimulation & & 3 & 6 & 2 & 4 & 0.323 \\
\hline \multicolumn{2}{|c|}{ Tachysystole } & 3 & 6 & 3 & 6 & 0.500 \\
\hline & 3 & 6 & 3 & 6 & 0.500 \\
\hline
\end{tabular}

\begin{tabular}{|c|c|c|c|}
\hline \multirow{2}{*}{ Apgar } & Group A & Group B & \multirow{2}{*}{ P-value } \\
\cline { 2 - 3 } & Mean \pm SD & Mean \pm SD & \\
\hline $1 \mathrm{~min}$ & $5.94 \pm 0.84$ & $5.42 \pm 1.44$ & 0.015 \\
$5 \mathrm{mins}$ & $7.16 \pm 0.87$ & $6.54 \pm 1.61$ & 0.009 \\
$10 \mathrm{mins}$ & $8.84 \pm 1.11$ & $8.02 \pm 1.88$ & 0.005 \\
\hline \multicolumn{3}{|c|}{ Table 6. Apgar Score of Neonates } \\
\hline
\end{tabular}

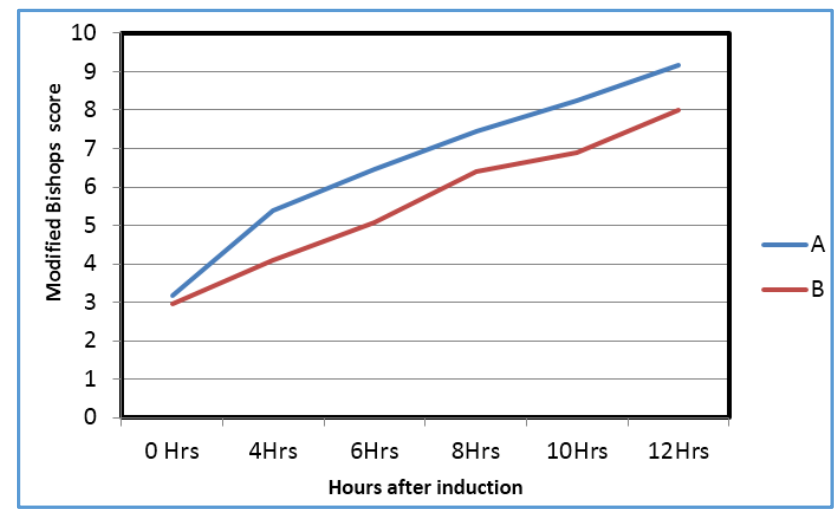

Figure 1. Improvement in Modified Bishop's Score with Time 


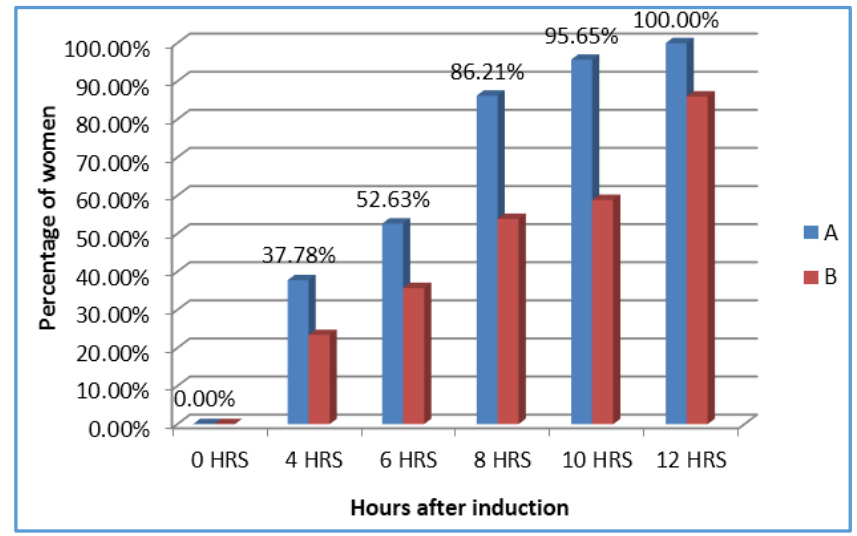

Figure 2. Cumulative Cervical Favourability with Time

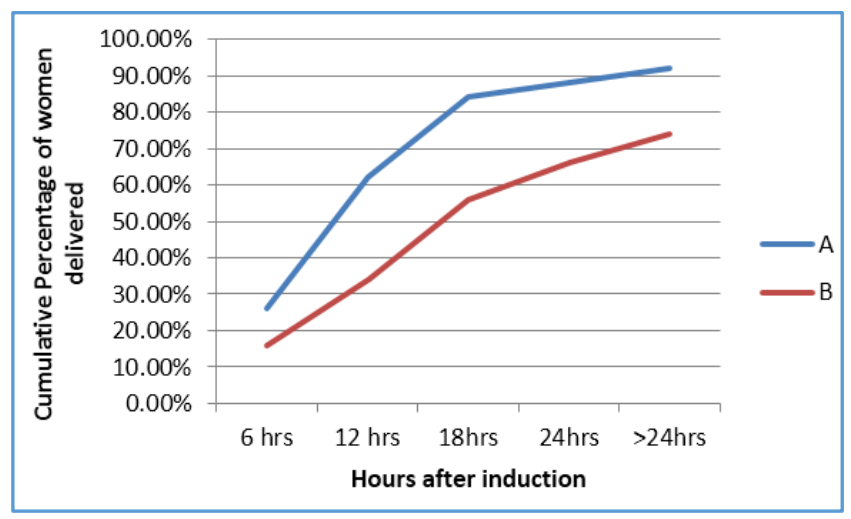

Figure 3. Cumulative Percentage of Women Delivered Vaginally

\section{DISCUSSION}

Labour induction at term gestation is the most common obstetric intervention of our times. Shorter induction to delivery time and quicker cervical priming is the need of hour in order to decrease the period of anxiety and discomfort for the patient and increased workload in hospitals. There is evidence that vaginal misoprostol is more efficacious than PGE2 gel and that oral misoprostol is more efficacious than vaginal route.6,9,10 There is limited good quality data on comparison of oral misoprostol with other inducing agents. Low dose oral misoprostol is the preferred mode, as it is easy and non-invasive. As we now have the 25 ugm tablet available that makes it even more convenient.

Innumerable regimes have been studied varying from single dose of $200 \mu \mathrm{g}$ to various titrations of misoprostol solutions.11-26 The frequency of administration and the use of oxytocin once cervical ripening is achieved are other variations noted in the literature.

In most studies, Bishop's scoring was done at $6 \mathrm{hrs}$. or at 6 and 12 hrs. both. However, we studied the Bishop's score and thus cervical favourability every 2 hrs. starting from 4 hrs. till $12 \mathrm{hrs}$. and it was found to be higher in misoprostol group at 4, 6, 8, 10 and 12 hrs. The same mean Bishop's score was achieved about 2 hrs. earlier in the misoprostol group as compared to the dinoprostone group as depicted in Figure 1. Also 100\% women achieved Bishop's more than 6, at $12 \mathrm{hrs}$. as contrast to $86 \%$ in dinoprostone group. In misoprost group $86 \%$ women already had a favourable score at $8 \mathrm{hrs}$., that is 4 hrs. earlier as can be seen in Figure 2. Thus, misoprostol was found to be more efficacious.

The mean induction to delivery interval in our study was about 3 hours shorter in Group A as compared to Group B $(10.4 \pm 6.31 \mathrm{hrs}$. and $13.17 \pm 7.34 \mathrm{hrs}$. respectively). Mean induction to delivery interval in various studies ranged from 10.2 to 24.9 hours in misoprostol group versus 14.8 to 28.7 hours in dinoprostone group. ${ }^{19-26}$ Though, most studies showed misoprostol give us a shorter induction interval compared to dinoprostone, the protocols used were different. As already discussed that cervical ripening occurred about 2 hours earlier, the moderate uterine contractions lasted about an hour less in the misoprostol group.

In our study vaginal delivery was achieved in $92 \%$ women in misoprostol group and $74 \%$ in dinoprostone group, which is similar to that observed by Gherman RB. ${ }^{23}$ In the misoprostol group 84\% women had delivered by 18 hrs., whereas only $56 \%$ delivered in the dinoprostone group (Figure 3). Studies done by Patil Kamal P24 and A Rouzi ${ }^{11}$ had also observed higher rate of vaginal delivery in misoprostol group. In literature, we found that vaginal delivery rate varied from 56 - 98.95\% for misoprostol and $45-91 \%$ in various studies.

In various studies, the rate of successful induction varies from 31 - 98\% with misoprostol and 32 - 98\% with dinoprostol.19-26 In present study successful induction, that is vaginal delivery within 24 hours was achieved in $88 \%$ women with misoprostol in contrast with $66 \%$ of women with dinoprostone gel. Failure of induction was $12 \%$ in misoprostol group and 34\% in dinoprostone group, which is similar to that observed by Patil Kamal P24 and A Rouzi. ${ }^{11}$ Failed induction has been reported to be $12 \%-68 \%$ with different misoprostol regimes and $28 \%$ - 67\% with dinoprostone gel. ${ }^{19-26}$

Caesarean section rate was significantly lower in misoprostol group as compared to dinoprostone group (8\% vs. $26 \%$ ). The caesarean delivery rate reported by various authors in literature ranges from $8-25 \%$ with misoprostol and $19-27 \%$ with dinoprostone. In a systematic review Kundodyiwa et al found lower caesarean rate with misoprostol compared with dinoprostone (20\% vs. $26 \%)^{27}$ In our study, we continued the use of misoprostol even after cervical ripening until the maximum 6 doses were used. The need of augmentation of labour with oxytocin in misoprostol group was lower ( $28 \%$ vs. $40 \%$ ), thus avoiding inconvenience to the patients of continuous drip and also reduced cost to hospital.

If we compare the cost effectiveness, a total of 196 tablets of misoprostol were required and 100 dinoprostone gels were used. The cost of tablets was Rs. 794 compared to Rs. 25,000 for the gel which is a huge difference.

Maternal complications between the two groups were similar. Higher dose of misoprostol has been associated with higher side effects in literature. ${ }^{1}$ In dinoprostone group $4 \%$ developed hyperstimulation and one woman developed severe bradycardia. Hyperstimulation developed in $6 \%$ in misoprostol group, but none developed foetal heart rate abnormalities. Kundodyiwa et al in their systematic review found no difference in hyperstimulation or further need of oxytocin. ${ }^{27}$ Neonatal birth weight was comparable in both 
groups. In misoprostol group no baby was affected with birth asphyxia, meconium aspiration and none needed NICU admission, while in dinoprostone group birth asphyxia (8\%), meconium aspiration (6\%) and NICU admission (6\%) were observed.

\section{CONCLUSION}

We thus conclude that by using low-dose misoprostol, rate of modified Bishop's score improvement was faster by about 2 hours and thus cervical ripening occurred about 2 hours earlier. Also 14\% more women reached cervical favourability with about $50 \%$ achieving so in $6 \mathrm{hrs}$. (contrast with 36\%). In misoprostol group, induction to delivery interval was shorter by 3 hours with 18\% higher vaginal delivery rate. Of those achieving vaginal delivery, $28 \%$ more women delivered at 18 hours. We saved about ?24,200 and women reported better VAS scores. It also has an advantage of decreasing the need of additional measures to achieve vaginal delivery. We thus recommend low-dose misoprostol as preferred ripening and inducing agent without fearing its efficacy safety and acceptability.

\section{REFERENCES}

[1] WHO. Recommendations for induction of labour. Geneva, World Health Organization, 2011.

[2] Caughey AB, Sundaram V, Kaimal AJ, et al. Maternal \& neonatal outcomes of elective induction of labour. Evidence Report/Technology Assessment (Full Rep) 2009;(176):1-257.

[3] Beigi A, Kazemipour SM, Tabarestani H. Induction of labour in term pregnancy \& 58: sublingual versus vaginal misoprostol. Tehran Univ Med J 2010;68(3):175-81.

[4] Crane JM, Delaney T, Butt KD, et al. Predictors of successful labour induction with oral or vaginal misoprostol. J Matern Fetal Neonat Med 2004;15(5):319-23.

[5] Gonen R, Degani S, Ron A. Prediction of successful induction of labour: comparison of transvaginal ultrasonography \& the Bishop score. Eur J Ultrasound 1998;7(3):183-7.

[6] Alfirevic Z, Keeney E, Dowswell T, et al. Methods to induce labour: a systematic review, network metaanalysis and cost-effectiveness analysis. BJOG 2016;123(9):1462-70.

[7] Society of Obstetricians and Gynaecologists of Canada. SOGC Clinical Practice Guideline No. 296. Induction of Labour, 2013.

[8] FIGO.

http://www.figo.org/sites/default/files/uploads/proj ect-

publications/Miso/Misoprostol_Recommended\%20Do sages\%202012.pdf

[9] Alfirevic Z, Aflaifel N, Weeks A. Oral misoprostol for induction of labour. The Cochrane Database of Systematic Reviews 2014;(6):CD001338.

[10] Alfirevic Z, Keeney E, Dowswell T, et al. Labour induction with prostaglandins: a systematic review and network meta-analysis. BMJ 2015;350:h217.
[11] Rouzi AA, Alsibiani S, Mansouri N, et al. Randomized clinical trial between hourly titrated oral misoprostol and vaginal dinoprostone for induction of labor. American Journal of Obstetrics and Gynecology 2014;210(1):56.e1-6.

[12] Souza AS, Feitosa FE, Costa AA, et al. Titrated oral misoprostol solution versus vaginal misoprostol for labor induction. International Journal of Gynecology and Obstetrics 2013;123(3):207-12.

[13] Thaisomboon A, Russameecharoen K, Wanitpongpan $P$, et al. Comparison of the efficacy and safety of titrated oral misoprostol and a conventional oral regimen for cervical ripening and labor induction. International Journal of Gynecology and Obstetrics 2012;116(1):13-6.

[14] Cheng SY, Ming H, Lee JC. Titrated oral compared with vaginal misoprostol for labor induction: a randomized controlled trial. Obstetrics \& Gynecology 2008;111(1):119-25.

[15] Hofmeyr GJ, Alfirevic Z, Matonhodze B, et al. Titrated oral misoprostol solution for induction of labour: a multi-centre, randomised trial. British Journal of Obstetrics and Gynaecology (Wiley) 2001;108(9):9529.

[16] Aalami-Harandi R, Karamali M, Moeini A. Induction of labor with titrated oral misoprostol solution versus oxytocin in term pregnancy: randomized controlled trial. Revista brasileira de ginecologia e obstetricia: revista da Federacao Brasileira das Sociedades de Ginecologia e Obstetricia 2013;35(2):60-5.

[17] Bricker L, Peden H, Tomlinson AJ, et al. Titrated lowdose vaginal and/or oral misoprostol to induce labour for prelabour membrane rupture: a randomised trial. BJOG: an International Journal of Obstetrics And Gynaecology 2008;115(12):1503-11.

[18] De A, Bagga R, Gopalan S, et al. The routine use of oxytocin after oral misoprostol for labour induction in women with an unfavourable cervix is not of benefit. Australian and New Zealand Journal of Obstetrics and Gynaecology 2006;46(4):323-9.

[19] Dallenbach P, Boulvain M, Viardot C, et al. Oral misoprostol or vaginal dinoprostone for labor induction: a randomized controlled trial. Am J Obstet Gynecol 2003;188(1):162-7.

[20] Dodd JM, Crowther CA, Robinson JS. Oral misoprostol for induction of labour at term: randomised controlled trial. British Medical Journal 2006;332(7540):509-13.

[21] Henrich W, Dudenhausen JW, Hanel C, et al. Oral misoprostol against vaginal dinoprostone for labor induction at term: a randomized comparison. Zeitschriftfur Geburtshilfe und Neonatologie 2008;212(5):183-8.

[22] Bartha JL, Comino-Delgado R, Garcia-Benasach F, et al. Oral misoprostol and intracervical dinoprostone for cervical ripening and labour induction: a randomized comparison. Obstet Gynecol 2000;96(3):465-9.

[23] Gherman RB, Browning J, O'Boyle A, et al. Oral misoprostol vs. intravaginal prostaglandin E2 for preinduction cervical ripening. A randomized trial. J Reprod Med 2001;46(7):641-6. 
[24] Kamal P, Swamy MK, Radhika RK. Oral misoprostol vs. intra-cervical dinoprostone for cervical ripening \& labour induction. J Obstet Gynecol India 2005;55:12831.

[25] Shetty A, Livingstone I, Acharya S, et al. A randomised comparison of oral misoprostol and vaginal prostaglandin E2 tablets in labour induction at term. BJOG 2004;111(5):436-40.
[26] Langenegger EJ, Odendaal HJ, Grove D. Oral misoprostol vs. intra-cervical dinoprostone for induction of labour. International J Gynecol 2005;88(3):242-8.

[27] Kundodyiwa TW, Alfirevic Z, Weeks AD. Low-dose oral misoprostol for induction of labor: a systematic review. Obstetrics and Gynecology 2009;113(2 Pt 1):374- 83. 